\title{
Espaços monstruosos: o Gótico na ficcionalização de Pedra Bonita e de Canudos
}

\author{
Hélder Brinate Castro ${ }^{a}$ \\ Godofredo de Oliveira Neto ${ }^{b}$
}

\begin{abstract}
Resumo
Ao contrário do que a crítica e a historiografia literárias dos séculos XIX e XX nos levam a crer, a literatura brasileira apresenta influxos góticos. Nesse contexto, a prosa regionalista desponta como uma ramificação mais desenvolvida da literatura de terror, horror $e$ suspense no Brasil, em que o interior do país, especialmente os sertões, se transforma em um autêntico locus horribilis. Nos romances $\mathrm{O}$ reino encantado: crônica sebastianista (1878), de Araripe Júnior, e Os Jagunços: novela sertaneja (1898), de Afonso Arinos, os narradores, ao utilizarem uma retórica macabra e horrorizante para descrever, respectivamente, os movimentos messiânicos de Pedra Bonita e de Canudos, constroem uma paisagem nordestina lúgubre e macabra. Em ambas as narrativas, o espaço não é apenas o palco em que se praticam e sofrem as atrocidades das tramas, mas também éo principal responsável pela constituição de uma atmosfera opressora e funesta. Enquanto $\mathrm{O}$ reino encantado descreve o sítio dos rituais da seita de Pedra Bonita de forma a provocar sentimentos de horror e ojeriza, Os Jagunços utilizam-se da natureza sertaneja para explicitar o terror dos soldados republicanos diante dos canudenses.
\end{abstract}

Palavras-chave: poética gótica; loci horribiles; literatura brasileira; movimentos messiânicos.

Recebido em: 29/08/2018 Aceito em: 19/11/2018

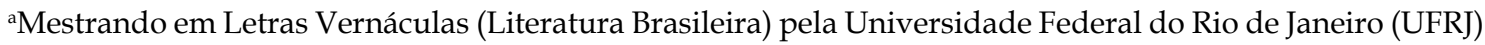
e bolsista CNPq. E-mail: helderbrinate@yahoo.com.br

'Professor de Literatura Brasileira na Universidade Federal do Rio de Janeiro (UFRJ) e pesquisador associado ao Centro de Pesquisas Sobre Países Lusófonos (CREPAL) da Université Sorbonne Paris Cité. E-mail: godolive@uol.com.br
} 


\section{A poética gótica e a literatura brasileira}

A ausência de univocidade do termo "gótico"1 reflete sua notável capacidade de se adaptar a contextos diversos (STEVENS, 2000; BOTTING, 2014). Uma rápida consulta a dicionários apontará, ao menos, quatro significados principais: (i) um adjetivo pátrio referente a uma das tribos germânicas responsáveis pelo declínio do Império Romano, os Godos; (ii) um termo renascentista empregado para nomear o estilo arquitetônico medieval, considerado "bárbaro", sem refinamento, em oposição à arte clássica; (iii) o grupo de romances e narrativas britânicas escritas entre 1764 e 1820, caracterizado pela produção de terror e/ou horror como efeito de recepção; e (iv) uma subcultura da arte e da moda contemporânea identificada pelo apreço às temáticas da melancolia, do terror e da morte.

A extensa e intricada história do vocábulo "gótico" parece

1 Ao longo deste trabalho, grafamos o termo "gótico" de três formas distintas, a saber: (i) entre aspas, (ii) com inicial maiúscula e (iii) com inicial minúscula. Quando utilizamos aspas ("gótico"), referimonos, propriamente, ao vocábulo "gótico", aplicando-o em seu sentido lato sensu. Ao empregarmos inicial maiúscula (Gótico), aludimo-nos à tradição literária inaugurada com a publicação de $O$ castelo de Otranto (1764), de Horace Walpole, a qual objetiva gerar medo, terror, horror, repulsa e emoções correlatas tanto no âmbito da diegese quanto no da exegese. Usamos, por fim, inicial minúscula (gótico) quando se trata do adjetivo concernente a essa tradição literária; dessa forma, Walpole é autor de um romance gótico, isto é, de uma narrativa que integra o Gótico (tradição literária). frustrar qualquer tentativa de conciliar seus conceitos mais restritos com seus sentidos mais amplos. No campo dos estudos literários, costuma-se, todavia, compreender o Gótico de acordo com duas perspectivas: uma que o considera como um gênero historicamente determinado, e outra, como uma tendência mais persistente e abrangente dentro da ficção como um todo. Conforme a primeira compreensão, o Gótico é um fenômeno histórico-literário, cujo auge, situado entre a segunda metade do século XVIII e o início do XIX, se caracteriza pela produção de uma ficção popular associada a uma visão sombria e decadente da vida, em que escritores como Horace Walpole, Ann Radcliffe, Mary Shelley e Matthew Lewis deixaram sua marca. Tal concepção não impossibilita a manifestação de revivalismos góticos nos séculos posteriores, pois, conforme David Stevens (2000, p. 31), o próprio Gótico Setecentista teria sido um revivalismo da preocupação com temáticas medievais e fantasiosas. A segunda perspectiva, por sua vez, considera o Gótico menos como um movimento artístico restrito a locais e momentos históricos específicos e mais como uma disposição do espírito moderno que alterou, significativamente, os modos de pensar, sentir e expressar a arte na modernidade. Trata-se, assim, de um fenômeno transcultural caracterizado por uma visão de mundo negativa e desencantada com a realidade. 
Compartilhando desta última concepção, Julio França (2017, p. 19-35) afirma que o Gótico seria a amálgama entre uma interpretação pessimista do mundo e uma linguagem artística altamente estetizada que, despontada no contexto cultural da segunda metade do século XVIII, se teria adaptado, em seus diversos revivalismos, às ansiedades e aos medos da sociedade moderna. O Gótico configura-se, pois, como uma faceta desiludida da natureza humana que transpassa múltiplas manifestações culturais e estabelece-se, no campo da arte, como uma poética negativa. Para Fred Botting,

A bondade, seja em termos morais, estéticos ou sociais, não
se faz presente nos textos góticos. É o vício que lhes interessa:
os protagonistas são egoístas ou maus; as tramas envolvem
decadência ou crime. Seus efeitos estéticos e sociais são
repletos de características negativas - não há beleza, nem
demonstrações de harmonia ou proporção. Deformados,
obscuros, feios, lúgubres e completamente avessos aos efeitos
do amor, da afeição ou dos prazeres nobres, os textos góticos
inscrevem a repulsa, o ódio, o medo, a aversão e o terror
(BOTTING, 2014, p. 2 . Tradução nossa). ${ }^{2}$

Com base nessa perspectiva, verifica-se que a produção ficcional brasileira, diferente do que evidenciam os estudos literários dos séculos XIX e XX, apresenta influxos da poética gótica, muitas vezes incompreendidos e menosprezados pela crítica nacional. Os motivos dessa ausência de relação não se dão pela inexistência de obras que explorem atmosferas lúgubres e ambientes decadentes, onde crimes e transgressões

2 "Gothic texts are not good in moral, aesthetic or social terms. Their concern is with vice: protagonists are selfish or evil; adventures involve decadence or crime. Their effects, aesthetically and socially, are also replete with a range of negative features: not beautiful, they display no harmony or proportion. Ill-formed, obscure, gloomy and utterly antipathetic to effects of love, admiration or gentle delight, gothic texts register revulsion, abhorrence, fear, disgust and terror" (BOTTING, 2014, p. 2). sociais ocorrem. França (2017, p. 20-21) identifica um complexo de causas e fatores para o "apagamento" da poética gótica nas Letras nacionais, entre os quais se destacam a preferência de nossos estudos literários por temas realistas e explicitamente relacionados com a identidade nacional, o pouco interesse da crítica por obras de cunho popular e a inexistência de uma produção sistemática de narrativas góticas em nossa literatura. A recepção de Noite na taverna (1855), de Álvares de Azevedo, constitui caso exemplar: a predominância de análises biografistas, psicológicas e pseudopsicanalíticas, que se voltaram para o homem Álvares e não para a obra, associou os elementos góticos de sua escrita a sua personalidade melancólica. Além disso, acusou-se o autor de uma suposta alienação quanto aos temas da realidade brasileira. É somente 
a partir de 1931, com o ensaio "A originalidade de Álvares de Azevedo", de Afrânio Peixoto, que se utiliza o termo "gótico" para se referir à obra do escritor romântico, que foi afiliado ainda a nomes como Hoffmann e Byron.

O episódio envolvendo o autor de Macário (1852) não configura evento exclusivo. É o que evidenciam os trabalhos empreendidos por diversos pesquisadores contemporâneos. Sandra Vasconcelos (2012) e Daniel Sá (2010) têm explorado a influência da poética gótica no Romantismo brasileiro, enquanto Alexander Meireles (2008) e Fernando de Barros (2014) demonstram que tal influxo se estende, pelo menos, até meados do século XX - seja na Belle Époque, seja no romance introspectivo. Mesmo o Naturalismo não escapou dessa influência, como indicam o trabalho de Maurício Menon (2007) e o de Marina Sena (2017).

Julio França (2017, p. 31-34) constata ainda seis pontos de contato entre a poética gótica e as Letras brasileiras. Conforme o pesquisador, as origens do romance no Brasil podem ter recebido influências do Gótico, uma vez que estudos, como os de Vasconcelos (2012), revelam ter havido grande circulação de romances ingleses no território brasileiro do início do século XIX. O Naturalismo constitui outra peça importante para compreender a manifestação da poética gótica no país. A interpretação das teorias de seleção natural de Darwin e do determinismo social de Taine proporcionou, por nossos escritores naturalistas, a criação de personagens que foram descritas como monstruosidades. Por outro lado, inspirados pela literatura decadente, que, como o Gótico, desvela um desencanto com a modernidade e uma recusa às tendências realistas, alguns de nossos autores tematizaram as perversões humanas, que culminam, não raro, na loucura, na degradação moral e na morte. Além disso, fronteiriça entre o jornalismo e a ficção, a literatura de crime brasileira conserva também elos com a poética gótica, cuja origem remonta ao nascimento dos romances policiais e das narrativas detetivescas. Os romances de sensação, imbricados entre as narrativas góticas e a ficção de crime, ao explorarem dramas repletos de mortes violentas, crimes aterrorizantes e eventos imprevisíveis, revelam, por sua vez, os excessos tão caros ao Gótico. Por fim, França (2017, p. 33-34) afirma que a tradição regionalista se demonstra profícua à poética gótica. Em suas vertentes fantásticas e realistas, 
alguns de nossos autores se utilizaram de recursos góticos para expressar o terror do imaginário popular e o horror da seca, da fome e da violência no sertão.

Barros (2014) também indica afinidades entre a poética gótica e a nossa prosa cujo enredo se desenvolve em locais interioranos. Ao estudar Casa-grande e senzala (1933), de Gilberto Freyre, A menina morta (1954), de Cornélio Penna, e Crônica da casa assassinada (1959), de Lúcio Cardoso, o pesquisador observa características do Southern Gothic, uma subcategoria do American Gothic, cujas histórias possuem como pano de fundo principal o antigo ethos senhorial e escravocrata do sul dos Estados Unidos (ELLIS, 2013, p. xx), em que as casas-grandes arruinadas ecoam a natureza decadente de seus habitantes. A poética gótica, na literatura brasileira, manifesta-se, assim, de forma semelhante: apresenta o legado fantasmagórico e violento de uma sociedade alicerçada no sistema rural e escravocrata, constituindo o que Barros (2014, p. 82) denomina Brazilian Gothic, o Gótico brasileiro.

França e Barros compartilham, portanto, do consenso quanto à presença da poética gótica em narrativas ambientadas nos sertões e nos ambientes rurais brasileiros. Menon (2007, p. 82), analisando o período entre 1843 e 1932, aventa ainda que,

[...] ao [se] tratar do regionalismo, do sertanismo ou das correntes a eles ligadas, há um maior destaque, por parte dos estudiosos, nos temas aqui trabalhados [o Gótico]. Seria esta uma ramificação mais desenvolvida da literatura de terror/ horror, suspense e mistério no Brasil? A julgar pela literatura do gênero desenvolvida na Europa, alimentada nas raízes dos contos populares, no cristianismo e na mitologia bárbara, há de se pensar que sim (MENON, 2007, p. 82).

O pesquisador constata que obras regionalistas/ sertanistas, ao tematizarem causos populares, misticismos e crenças de uma população caracterizada pelo sincretismo religioso, podem conter traços da literatura gótica, sobretudo da que explora eventos sobrenaturais, sejam eles explicados ou não. A essa reunião de distintas heranças culturais - as tradições nativas, com seus mitos e costumes; os folclores e lendas europeus; e os rituais africanos e seu panteão de entidades da natureza -, somam-se o isolamento das regiões rurais e, por conseguinte, o alheamento quanto a explicações científicas, que se desenvolviam no litoral brasileiro da segunda 
metade do século XIX e dos princípios do XX. Os regionalismos brasileiros não apenas abordaram temas ligados ao terror, horror ou suspense, mas, muitas vezes, fizeram dessas temáticas a matéria essencial de algumas de suas narrativas. O clima lúgubre e sombrio, propício ao desenrolar de tramas góticas, não se restringe, pois, às ambientações europeias e estadunidenses, mas se faz também presente no Brasil, seja na mata fechada, nos pampas gaúchos ou na vegetação que exausta sob um sol imperioso.

Dos muitos elementos comuns entre as Letras brasileiras e a ficção gótica, há, pelo menos, cinco pontos que surgem como fundamentais: (i) a construção de espaços narrativos como loci horribiles; (ii) a relação fantasmagórica com o passado, que ressurge para assombrar o presente; (iii) a caracterização de personagens como monstruosidades devido à própria natureza humana ou às psicopatologias; (iv) o desenvolvimento de enredos que exploram, tanto no plano da diegese quanto no da recepção, efeitos melodramáticos e emocionais; e (v) a utilização contínua de campos semânticos relacionados à morte, à morbidez e à degeneração física e mental. Tendo em vista a limitação espacial e os objetivos do presente ensaio, focalizar-se-á o primeiro tópico, ainda que os demais sejam explorados ao longo do estudo.

\section{O espaço no Gótico literário}

O espaço é um elemento central nas narrativas góticas. Em muitos casos, é personificado, tornando-se ele mesmo uma monstruosidade capaz de gerar seus próprios monstros. O locus horribilis pode ser, de fato, considerado um topos do Gótico literário, uma vez que não são raras as narrativas que tematizam locais sinistros, principalmente castelos, casarões arruinados, espaços religiosos, florestas e cidades labirínticas. Essas localidades, evocando emoções de encarceramento e poder, situam-se normalmente em regiões isoladas, fora do alcance da lei e da autoridade civilizadas, o que as torna ambientes sem proteção contra o terror, onde a escuridão e a estrutura desordenada estimulam medo e fantasias irracionais.

Durante o século XVIII, o Gótico tinha o castelo como seu principal espaço narrativo, o que se pode comprovar pela frequência com que o vocábulo "castelo" aparece em títulos de 
3 "The number of romances published in the fifty years following Otranto which proclaimed the word Castle in their titles is a striking proof of the immense importance of the Castle in the Gothic Novel" (SUMMERS, 1964 apud LACÔTE, 2015, p. 202).

4 "Like Walpole, her geographical settings were usually in southern European countries, Italy and France in particular $[. .$.$] . The$ physical settings, too, were suitably Gothic: isolated and ruined castles and abbeys, old chateaux with secret vaults and passageways, dark forests and spectacular mountain regions populated by bandits and robbers" (BOTTING, 1996, p. 41). inúmeros romances. Tomemos como exemplos os casos de $O$ castelo de Otranto (1764), de Horace Walpole; Emmeline, a orfã do castelo (1788), de Charlotte Turner Smith; e Os castelos de Athline Dunbayne (1789), de Ann Radcliffe (cf. LACÔTE, 2015). Summers (1964) comenta tal fato: “O número de romances publicados nos cinquenta anos que se seguiram a Otranto, que declaram a palavra castelo em seus títulos, é uma prova surpreendente da imensa importância do castelo para o romance gótico" (SUMMERS, 1964 apud LACÔTE, 2015, p. 202. Tradução nossa) $)^{3}$.

Caracterizada frequentemente como local malassombrado, essa construção medieval serve de espaço para acontecimentos sobrenaturais. Lembremo-nos dos clássicos episódios da morte de Conrad, de $O$ castelo de Otranto, esmagado pela queda de um elmo gigante, e da aparição, em uma cripta, do fantasma desta personagem a seu pai. Em O Monge (1796), de Matthew Lewis, o castelo de Lindenberg é palco da lenda de Bleeding Nun, uma das tramas paralelas do romance do escritor inglês. Não nos esqueçamos de que, mesmo em Os mistérios de Udolpho (1794), de Ann Radcliffe, pertencente à vertente gótica do sobrenatural explicado, há exemplos dignos de nota, como a misteriosa música de origem inidentificável, ouvida pela protagonista do romance, Emily, que conjectura que a melodia é reproduzida por Valancourt, seu interesse amoroso. A respeito de Radcliffe, Fred Botting comenta:

Tal como Walpole, seus [de Ann Radcliffe] ambientes geográficos eram normalmente localizados nos países do sul da Europa, particularmente Itália e França. [...]. Os ambientes físicos eram também adequados ao Gótico: abadias e castelos arruinados e isolados, velhos castelos com criptas e passagens secretas, florestas obscuras e regiões montanhosas espetaculares, povoadas por bandoleiros e ladrões (BOTTING, 1996, p. 41. Tradução nossa). ${ }^{4}$

Tais espaços inspiram medos e ameaças. Fazem-no, porém, não apenas por meio de suas características físicas e concretas. As percepções subjetivas dos indivíduos sobre os locais também configuram importante fator tanto para a gênese quanto para a intensificação de apreensões e pavores. As percepções não são, todavia, somente idiossincráticas, mas respondem a certas condições culturais, do que se depreende a complexidade das paisagens do medo (TUAN, 2005, p. 12), dependentes da consubstanciação de aspectos objetivos do 
5 "'There,' said Montoni, speaking for the first time in several hours, 'is Udolpho.'

Emily gazed with melancholy awe upon the castle, which she understood to be Montoni's; for, though it was now lighted up by the setting sun, the gothic greatness of its features, and its mouldering walls of dark grey stone, rendered it a gloomy and sublime object. As she gazed, the light died away on its walls, leaving a melancholy purple tint, which spread deeper and deeper, as the thin vapour crept up the mountain, while the battlements above were still tipped with splendour. From those too, the rays soon faded, and the whole edifice was invested with the solemn duskiness of evening. Silent, lonely and sublime, it seemed to stand the sovereign of the scene, and to frown defiance on all who dared to invade its solitary reign. As the twilight deepened, its features became more awful in obscurity, and Emily continued to gaze, till its clustering towers were alone seen, rising over the tops of the woods, beneath whose thick shade the carriages soon after began to ascend.

The extent and darkness of these tall woods awakened terrific images in her mind, and she almost expected to see banditti start up from under the trees. At length, the carriages emerged upon a heathy rock, and, soon after, reached the castle gates, where the deep tone of the portal bell, which was struck upon to give notice of their arrival, increased the fearful emotions that had assailed Emily" (RADCLIFFE, 2008, p. 226-227). espaço físico com a subjetividade do espaço psicológico. No caso da literatura, as idiossincrasias geofísicas e socioculturais subordinam-se sempre à perspectiva de quem os presencia e/ou descreve (narradores e personagens) e à de quem os experimenta (personagens e leitores). Tomemos como ilustração de uma paisagem do medo a seguinte descrição do castelo de Os mistérios de Udolpho:

"Lá", disse Montoni, falando pela primeira vez em muitas horas, "está Udolpho".

Emily contemplou, com um terror melancólico, o castelo, que compreendeu ser de Montoni; embora fosse iluminado pelo pôr do sol, a grandeza gótica de seus traços e os seus arruinados muros de pedras cinza tornavam-no sublime e sombrio. Conforme ela olhava, a luz desaparecia das muralhas, deixando uma melancólica cor roxa que se espalhava e ficava cada vez mais escura enquanto as ameias acima ainda mantinham o esplendor. Destas também os raios de sol desvaneceram prontamente e todo o edifício foi envolvido pela solene escuridão da noite. Silencioso, isolado e sublime, o castelo parecia o soberano da cena e desafiava a todos que se atrevessem a invadir seu reino solitário. À medida que o crepúsculo adensava, os aspectos da construção tornavam-se mais horríveis na escuridão, e Emily continuava a contemplar até que somente as torres aglomeradas fossem vistas, erguendo-se sozinhas sobre os topos das árvores, sob as quais densas sombras de carruagens começavam a subir.

A extensão e a escuridão das altas árvores despertaram espantosas imagens na mente de Emily, que quase esperou o surgimento de bandidos escondidos entre a floresta. Ao longe, as carruagens apareceram sobre uma rocha com vegetação rasteira e, logo após, alcançaram os portões do castelo, onde o intenso som do sino do portal, balançado para avisar da chegada da comitiva, aumentou as terríveis emoções que assolavam Emily (RADCLIFFE, 2008, p. 226227. Tradução nossa). ${ }^{5}$

Na passagem, o castelo, situado à beira de um precipício, é descrito durante o crepúsculo, acentuando seu aspecto sombrio, misterioso e sublime. Sob a perspectiva abatida da heroína do romance, a construção torna-se mais ameaçadora, o que ocorre, principalmente, pelo emprego constante de vocábulos associados ao campo semântico da morbidez e da degradação, como "arruinados", "sombrio", "melancólica", "horríveis", "sombras" etc. O edifício desvelava-se ainda 
de forma a sugerir a possibilidade de ser um local malassombrado, palco de transgressões morais e físicas, o que se confirma ao longo do romance: o encarceramento de Emily e o cruel tormento de sua tia, que sucumbe à perversidade de Montoni, constituem acontecimentos que intensificam o caráter nocivo do lugar. O castelo de Udolpho emerge, assim, como um dos mais eminentes loci horribiles da produção radcliffeana e também do Gótico literário.

\section{O espaço gótico dos movimentos messiânicos brasileiros}

Enquanto o Gótico Setecentista explora castelos e mosteiros arruinados para evocar emoções de encarceramento e poder, a literatura brasileira da segunda metade do século XIX tem os sertões e os ambientes rurais do Brasil como um de seus principais loci horribiles. Longe de servir somente como pano de fundo para a composição da "cor local", tais localidades constituem fator essencial para as narrativas com influxos góticos ali ambientadas.

Se, na literatura gótica europeia, o clima enevoado e frio propicia a gênese de cenários melancólicos e amedrontadores, na literatura brasileira, o sertão desconhecido, desabitado e isolado induz a criação de paisagens ameaçadoras e soturnas. Euclides da Cunha, n'Os sertões (1902), aponta tal paralelo: "Há, ali [o sertão nordestino], toda a melancolia dos invernos, com um sol ardente e os ardores do verão!" (CUNHA, 2011, p. 56). Na região brasileira de clima tropical semiárido, com temperaturas elevadas e com os menores índices pluviométricos do país, alguns autores do Oitocentos encontraram solo fértil para a produção de uma literatura capaz de gerar o medo artístico, em que técnicas narrativas típicas da poética gótica se mostram essenciais.

Além de essas localidades apresentarem condições topoclimáticas adversas à vida humana, seu isolamento e, por conseguinte, seu alheamento a uma educação formal e às explicações científicas divulgadas no litoral brasileiro da segunda metade do século XIX acentuam a crença das populações sertanejas e rurais em lendas e superstições, o que conforma contexto propício para a manifestação de topoi góticos. É de se esperar, portanto, que a ficcionalização de movimentos messiânicos, marcados por episódios de crença extremada e 
de repressões truculentas, atribua características sombrias, fúnebres e grotescas a ritos e rituais de bases sociorreligiosas, pintando, assim, um quadro típico das narrativas góticas.

Nos romances $O$ reino encantado: crônica sebastianista (1878), de Tristão de Alencar Araripe Júnior, e Os Jagunços: novela sertaneja (1898), de Olívio Barros (pseudônimo de Afonso Arinos de Melo Franco), os narradores, ao se utilizarem de uma retórica macabra e horrorizante para descrever, respectivamente, os movimentos messiânicos de Pedra Bonita/ Pedra do Reino e de Canudos, constroem uma paisagem nordestina lúgubre e obscura, transformando o sertão em um autêntico locus horribilis. Em ambas as narrativas, o espaço não é apenas o palco em que se praticam e sofrem as atrocidades das tramas, mas também é o principal responsável pela constituição de uma atmosfera opressora e funesta. Se $O$ reino encantado descreve o sítio dos rituais místicos da seita de Pedra Bonita de forma a provocar sentimentos de horror e medo, Os Jagunços, por sua vez, utilizam-se da natureza sertaneja para explicitar o terror dos soldados republicanos diante dos canudenses, que parecem fundir-se à hostil vegetação local, conferindo-lhes aspecto sobrenatural.

O livro do aclamado crítico literário narra as desventuras do fazendeiro Bernardo de Vasconcelos, que, além de ter suas fazendas destruídas, tem sua filha, Maria, raptada pelos membros da seita sebastianista, os também autores da ruína de suas propriedades. Com o intuito de resgatá-la, Vasconcelos, com a ajuda de alguns de seus subordinados e de integrantes da Igreja e do governo, organiza uma comitiva que enfrenta uma árdua jornada pelo sertão nordestino até adentrar Serra Formosa, onde ocorrem os rituais de Pedra Bonita. Ao longo do trajeto, as personagens sentem-se amedrontadas e intimidadas. Tais sentimentos se exacerbam ainda mais à medida que se aproximam do local. É, contudo, a partir da descrição do arraial de Pedra do Reino, sob a perspectiva de Manuel Velho, feitor de Vasconcelos, que se condensa e se revela explicitamente o medo sentido pelos indivíduos não sebastianistas diante do movimento messiânico:

Dirigindo suas vistas para a esplanada, Manuel Velho, cujos cabelos erguiam-se sob o chapéu de couro, quase caiu agitado por uma convulsão que percorreu-lhe todo o corpo. 
Mil visões e avantesmas passaram-lhe pelos olhos.

E o quadro não era para menos... Havia em tudo quanto o circundava um aspecto pavoroso, que crescia à proporção que se avisinhava dos rochedos. Entre estes, no fundo da tela, suspendiam-se, destacando-se do resto, duas gigantescas rochas quase iguais na altura, retas, separadas entre si por um mui pequeno interstício, que pela alvura assemelhavamse a dois fantasmas envolvidos em amplas mortalhas. Por capricho do acaso acontecia que, ao tempo em que Manuel desembocava na esplanada, o globo prateado da lua, colocando-se por trás desses duendes de granito, cercavaos de uma espécie de auréola diáfana, esbranquiçada, projetando a sua sombra imensa até onde estavam os nossos observadores (ARARIPE JÚNIOR, 1878, p. 60).

Ao se deparar com o povoado, Manuel Velho apavora-se de forma similar a Emily quando esta contempla o castelo de Udolpho. Enquanto a heroína do romance de Radcliffe possui uma disposição anímica sensível e frágil, o feitor da narrativa de Araripe Júnior mostra-se destemido, o que não o impede, porém, de se horrorizar diante das duas pedras que, conforme os adeptos da seita, seriam as torres da catedral enterrada. Aponta-se, pois, que o arraial de Pedra Bonita é tão assombroso e ameaçador que, perante ele, os mais corajosos feitores do sertão sucumbem. Para tal, o narrador, ao empregar vocábulos do campo da morte e do sobrenatural, descreve as rochas como fantasmas e duendes, cuja aparência ganha contornos mais aterrorizantes sob a luz diáfana de um luar nebuloso, reforçando os aspectos sobrenaturais e soturnos do local. Conforma-se, assim, um legítimo locus horribilis, que aguça o sentimento de medo da personagem e, por extensão, do leitor.

Se n'O reino encantado, o povoado de Pedra do Reino é o principal locus horribilis da trama, n'Os Jagunços, todo o sertão da Bahia se recobre de aspectos fúnebres, em especial durante os inúmeros embates travados entre os canudenses e as tropas do governo, como se nota no seguinte excerto:

[...] Para os soldados havia qualquer coisa de estranho, ou de sobrenatural naquela subitânea e tremenda agressão.

Em vão, seus olhos, depois de rápido encontro, muitas vezes corpo a corpo com o inimigo, pesquisavam o campo e penetravam perscrutadores na sombra das caatingas: tudo parecia silencioso e deserto. Nem o mais leve palpitar de asas de um pássaro alvoroçado vinha dar uma nota de vida à solidão; as próprias árvores, mudas e tristonhas, 
com as folhas de um verde tirante a amarelo; as próprias árvores, mesquinhas, de tronco rugoso e cinzento, como que estortegadas na luta contra a dureza e a sequidão da terra ingrata - soerguiam-se do solo com ar de desconfiança e de hostilidade.

Toda aquela região deserta e morta, áspera e brutesca sacudia-se de repente vomitando tiros, derramando na força invasora o pavor do assombramento, e logo depois recolhiase na mudez e na solidão.

Já então os soldados viam por toda a parte sombras de inimigos; cada tronco parecia abrigar um poder invisível de agressão e de morticínio [...].

A tarde ensanguentara o céu, e os raios do sol no declínio rasgavam as nuvens como longas espadas refulgentes.

[...]

A aproximação da noite, a ameaça da treva, criava na paisagem formas temerosas e levantava sons inauditos, que pareciam silvos de cobras, vozes de morcegos, ranger de ferro e pracatar de passos correndo (FRANCO, 1898, p. 200-201).

No momento da batalha com as tropas republicanas, os membros de Canudos adquirem feições sobrenaturais, fundindo-se à própria flora sertaneja, caracterizada como sorumbática e tortuosa devido à adversidade do sertão baiano ao ser humano. Diante da região desconhecida, qualificada como "deserta e morta, áspera e brutesca", e do hábil jagunço, os soldados republicanos apavoram-se e perdem a luta, cuja violência se reflete na descrição do crepúsculo com cor vermelho-sangue e com raios de sol cortantes. O anoitecer traz ainda outras adversidades: a ameaça das trevas para os agentes do governo, que se encontram em uma terra onde os sons dos animais acentuam o caráter sobrenatural e atemorizante da noite, aguçando-lhes o instinto de proteção; o perigo está em toda a parte, porém não se pode vê-lo nem combatê-lo.

Além de toda a região sertaneja, Os Jagunços apresentam um locus horribilis específico: as ruínas do povoado de Belo Monte. Com os sucessivos ataques do governo ao arraial, inúmeros canudenses eram assassinados "e os cadáveres ficavam nos lugares onde caíam" (FRANCO, 1898, p. 402), transformando a cidade santa em um cemitério a céu aberto. Os constantes incêndios e tiros de canhões arruinaram Canudos, sobrando apenas os destroços e esqueletos das habitações. Ao final do embate, a urbe de Antônio Conselheiro reduz-se a 
um autêntico locus horribilis, onde as igrejas, derruídas pelos canhões do governo, se assemelham às ruínas dos castelos e mosteiros do Gótico Setecentista:

O bombardeio fazia-se diariamente, e a igreja nova, de preferência alvejada, já tinha perdido uma das torres. Seus muros, porém, continuavam ainda de pé, sombrios e ameaçadores. Em roda do templo, montões de pedra se acumulavam. Ninguém, das forças sitiantes, compreendia como podiam abrigar-se no temeroso reduto homens que desafiavam a morte. Parecia, às vezes, que as próprias pedras e os escombros da igreja mutilada respondiam ao fogo inimigo com outro fogo mais terrível ainda.

Um espírito das trevas animava aquela mole de pedra, transformando-a em miríades de balas contra as tropas.

Pelas manhãs suaves, ou nas tardes arraiadas de cores gloriosas, o templo-reduto emergia dentre as casinhas de Belo Monte, como uma águia negra ferida, de garras prontas à luta e asas abertas em defesa da prole perseguida (FRANCO, 1898, p. 402).

Apesar de arruinada, a igreja nova, com seus muros "sombrios e ameaçadores", figurava, ao olhar dos exauridos soldados republicanos, um ente sobrenatural que os atacava de forma terrível e incompreensível. Similar aos castelos e aos mosteiros/conventos derruídos das típicas narrativas góticas, $\mathrm{o}$ "temeroso" reduto religioso de Canudos evocava medo, terror e horror à tropa do governo, o que é explicitado pela imagem altiva e hostil da águia negra que luta, com suas garras, contra as forças do inimigo. Na passagem, o santuário, além de ser descrito como um locus horribilis, uma paisagem lúgubre, inquietante e decadente, representa a resistência do movimento messiânico, tal nos lembra Euclides da Cunha em sua Magnum Opus (2011, p. 578): “Canudos não se rendeu. [...] resistiu até ao esgotamento completo. Expugnado palmo a palmo, na precisão integral do termo, caiu no dia 5, ao entardecer, quando caíram os seus últimos defensores, que todos morreram".

\section{Considerações finais}

O reino encantado: crônica sebastianista e Os Jagunços: novela sertaneja configuram, portanto, apenas duas das inúmeras narrativas brasileiras dos finais do século XIX que se utilizaram de topoi góticos. Contrariando a crítica e a historiografia 
tradicionais, ambos os romances demonstram que nosso apreço por temas realistas e relacionados com a identidade do Brasil não exclui o emprego de técnicas narrativas tipicamente associadas ao irreal, ao sobrenatural e à fantasia. Ao contrário, eles evidenciam a proficuidade de tais estratégias de escrita na ficcionalização de temas identitários do país, já que os movimentos messiânicos de Pedra Bonita e de Canudos adquirem, respectivamente, nas escritas de Araripe Júnior e de Afonso Arinos, aspectos tétricos e sombrios, despontando o sertão nordestino como um local inóspito, sobrenatural, ameaçador e adverso ao homem do litoral brasileiro.

Em meio ao calor tropical das Letras brasileiras, presenciam-se, pois, sombrias figurações da poética gótica, mais especificamente, como se procurou demonstrar, da composição do característico locus horribilis. Da convergência de aspectos físicos e concretos dos povoados de Pedra Bonita e de Belo Monte com as características anímicas das personagens e dos narradores, $O$ reino encantado e Os Jagunços ficcionalizam dois importantes acontecimentos da História brasileira de forma a gerar, tanto no plano diegético quanto no exegético, paixões intensas, como o horror, o terror e o medo.

\section{REFERÊNCIAS}

ARARIPE JÚNIOR, Tristão de Alencar. O reino encantado: crônica sebastianista. Rio de Janeiro: Tipografia da Gazeta de Notícias, 1878.

BARROS, Fernando Monteiro de. Do castelo à casa-grande: o "Gótico brasileiro", em Gilberto Freyre. Revista Soletras, São Gonçalo, n. 27, p. 80-94, jan./jun., 2014.

BOTTING, Fred. Gothic. London: Routledge, 1996. . Gothic. 2. ed. London: Routledge, 2014.

CUNHA, Euclides da. Os sertões. Rio de Janeiro: Nova Fronteira, 2011 [1902].

ELLIS, Jay (Ed.). Southern Gothic Literature (Critical Insights). Ipswich, Massachussetts: Salem Press; Amenia, NY: Grey House Publishing, 2013. 
FRANÇA, Julio. Introdução. In: (Org.). Poéticas do mal: a literatura do medo no Brasil (1840-1920). Rio de Janeiro: Bonecker, 2017. p. 19-35.

FRANCO, Afonso Arinos de Melo. Os Jagunços: novela sertaneja. v. 1 e 2. São Paulo: O Comércio de S. Paulo, 1898.

LACÔTE, Fanny. Gothic architecture, castles and villains: transgression, decay and the Gothic locus horribilis. In. ERMIDA, Isabel (Org.). Dracula and the Gothic in literature, pop culture and the arts. Leiden: Brill Rodopi, 2015. p. 199-217.

MEIRELES, Alexander. O admirável mundo novo da república velha: o nascimento da ficção científica brasileira no começo do século XX. 2008. 193 f. Tese (Doutorado em Ciência da Literatura) - Faculdade de Letras, Universidade Federal do Rio de Janeiro, Rio de Janeiro.

MENON, Mauricio César. Figurações do gótico e de seus desmembramentos na literatura brasileira; de 1843 a 1932. 2007. 216 f. Tese (Doutorado em Letras) - Faculdade de Letras, Universidade Estadual de Londrina, Londrina.

PEIXOTO, Afrânio. A originalidade de Álvares de Azevedo. Revista Nova, São Paulo, ano I, n. 3, p. 355-374, 15 set. 1931.

RADCLIFFE, Ann. The Mysteries of Udolpho. Oxford: University Press, 2008.

SÁ, Daniel Serravalle. Gótico Tropical. Salvador: Edufba, 2010.

SENA, Marina Faria. O Gótico-Naturalismo na literatura brasileira oitocentista. 2017. 99 f. Dissertação (Mestrado em Teoria da Literatura e Literatura Comparada) - Instituto de Letras, Universidade do Estado do Rio de Janeiro, Rio de Janeiro.

STEVENS, David. The Gothic Tradition. Cambridge: Cambridge University Press, 2000.

TUAN, Yi-Fu. Paisagens do medo. Tradução de Lívia de Oliveira. São Paulo: Editora UNESP, 2005.

VASCONCELOS, Sandra. Sentidos do demoníaco em José de Alencar. Ilha do Desterro, v. 62, p. 271-292, 2012. 


\section{Abstract \\ Monstrous spaces: Gothic in fictionalization of Pedra Bonita and Canudos}

Despite of what Brazilian literary criticism and historiography of $19^{\text {th }}$ and $20^{\text {th }}$ centuries declare, Gothic can be found in Brazilian literature. Recent studies have shown that regionalist fiction is one of the most developed proses in Brazilian terror, horror and thriller literature, characterizing the up-country, specially the sertões, as an authentic locus horribilis. In the novels O reino encantado: crônica sebastianista (1878), by Araripe Júnior, and Os Jagunços: novela sertaneja (1898), by Afonso Arinos, their narrators, to describe the messianic movements of Pedra Bonita and Canudos respectively, use a horrifying and macabre language to turn the Brazilian Northeastern landscape into a gloomy and obscure scenery. Both narratives explore the space not only as the stage in which the atrocities of the plots are practiced and suffered, but also as the main narrative element that constitutes an oppressive and fatal atmosphere. While $\mathrm{O}$ reino encantado describes the place of Pedra Bonita's rituals to evoke feelings of horror and fear, Os Jagunços uses the sertaneja nature to demonstrate the republican soldiers' terror in front of the canudenses.

Keywords: gothic poetics; loci horribiles; Brazilian literature; messianic movements. 